\title{
Study on the Present Developing Status and the Problems of Facility Agriculture in Longdong -----Take Xiao-Jin Vegetable Base For Example \\ Weiwei Guo
}

\author{
Economics and management college of Longdong university, Qingyang Gansu, 745000
}

\author{
Keywords: Xiao-Jin vegetable base, Facilities agriculture, Shacks construction
}

\begin{abstract}
Developing high-yield, high-quality, high efficient and environment friendly modern agriculture and improving the efficiency of unit land output, is fundamental to solve the problem of one billion three hundred million people for dinner. The paper for the example of Xiao jin facilities vegetable base describes the present development status of xiao jin vegetable base facility agriculture; analyses a series of problems of existing in the development of facilities agriculture, including owners backward perception, the scattered management right, poor sales, poor infrastructure, the shortage of technical personnel, financing difficulties; puts forward the scale management, the government propaganda promotion, improves consciousness cultivation, and a series of countermeasures to promote the development of longdong region agricultural facilities.
\end{abstract}

\section{Introduction}

The fact of more population, less land and less reserve resources is the basic national conditions of our country's land resources. How to use effective cultivated land resources to meet the growing feeding problem, is the theme of world peace and development, is the focus of human. As early as 2000, six hundred and sixty-six counties all over the country had been broke through the warning line of cultivated land per capita zero point eight mu of the United Nations food and agriculture organization, of which four hundred and sixty-three counties had less than zero point five mu of cultivated land per capita. Under the basic national conditions, developing the high-yield, high-quality, high efficient and environment friendly modern agriculture and improving the efficiency of unit land output is fundamental to solve the problem of one billion three hundred million people for dinner. With the rapid advance of urbanization process, cultivated land area is reduced year by year in longdong. According to 2015 statistics, per capita arable land has been changed from early 2000 acres more than 2 to 1.5 acres around now. Therefore, the development of cycle agriculture demonstration area of vegetable base facilities agriculture base is the long-term and wise plan.

\section{First, the Present Developing Status of Facility Agriculture in Longdong}

Xiao-jin facilities vegetable base is one of xifeng district of the city and countryside integration industry breeding projects, including six administrative villages, respectively, wangzhuang town, mi king, ruiling, hezui, licheng, zhangzhuang, it's a total of $20000 \mathrm{mu}$ of land, and a total investment of $¥ 800$ million. The bases have 6000 fifth generation solar greenhouse of a string type without pillar, which the area is $15000 \mathrm{mu}$, have $3000 \mathrm{mu}$ double string beam without steel canopy, and post office, display areas and roads covered $2000 \mathrm{mu}$. As efficient agricultural demonstration zone, the bases formed a specialized management services office, including a technical guidance and training services, market information collection, tent area daily maintenance, credit support, member training, new varieties and new technology introduction and promotion, etc. All these departments support the development of the bases, and have made considerable gains. According to the eternal life to fruit and vegetable seedling planting farmers' professional co-operatives research practice, owners contracted to shed 110 revenue of 110 yuan in 2016, shed all income is 50000 yuan above, shed all profit is 20000 yuan. If all greenhouses base have the business performance budget, so the whole xiao jin vegetable base will generate an income of 300 million yuan, the profits will be 
100 million yuan, the development trend is bound to accelerate the regional farmers out of poverty to become rich, achieve a steady increase in rural incomes, and drive the development of local economy.

\section{Second, Agricultural Development Problems Analysis in Longdong.}

Agricultural facilities although started late in Longdong, such as xiao jin facilities for completion by the end of 2010, the recycling agriculture demonstration zone vegetables bases of YanQi built in the end of 2012, but due to the government attaches great importance to the construction, and coordinate to deal with the interests of all parties, and make overall arrangement of construction scale, so has made considerable achievements in several years. All has made great achievements in promoting the optimization and upgrading of industrial structure of agriculture and achieving characteristic agriculture to strengthen town (township), promoting regional economic development, driving the economic efficiency of agriculture and increasing farmers' income, improving people's living standard, etc. Of course, we also found backward perception, scattered management right, poor sales, poor infrastructure, and shortage of technical personnel, financing difficulties, and a series of problems to restrict the further development.

(1) Poor infrastructure of tent area

The first phase of Xiao-jin facilities vegetable base was founded in 2010, it had been more than six years. After the completion, it had experienced different owners contract, the contractors have been used to the early infrastructure, not improved the vegetable greenhouses regional infrastructure, even not maintained vegetable greenhouses skeleton. According to a recent survey, we found that the infrastructure exists at least the following four aspects of problems in the tent area. (1)tent area has not yet hardened roads, and not plan parking lots and parking spaces, the cars are not easy to be in and out, seriously limited the tent area to carry out the ability of leisure agriculture, unfavorable to shed area of expansion and brand image promotion.(2) the tent area have not been built public toilets, restaurants, shops and other supporting facilities, all these will not conduce to tourism and experience visitors stay tent area for a long time for picking or dining, shopping, etc. (3)the roads passing into the tent are without the corresponding sign, for tourists or come for the first time visitors find the location of the community. (4) the first phase projects completed greenhouses have been damaged to varying degrees, which was badly damaged the skeleton, films, part of the shed door, window, bearing back wall appears different levels of problems. Greenhouses skeleton, for example, the former is mainly composed of bamboo, but life is short, need to replace 2 years on average, cost is high, the consumption of manpower, easy to deformation, in winter snow, or even collapse. And the thin wall steel tube prefabricated canopy on the market has become a mainstream trend, to a certain extent can overcome the defects greenhouses bamboo and wood structure. But most tent area greenhouse owners because of funding problems have been improved.

(2) Poor health environment around tent area

The beautiful natural environment can often make people happy, linger, and the tent area natural environment is poor in many ways now. Because the contractions of the tent area are not disposable, so the tent area public health area was or weeds, or garbage dumps, or sewage clusters, seriously affected the image of demonstration area. Because some shelters are away from the road, the tent area roads are too narrow, bad for vehicles, unable to rent out for a long time, water has been submerged by weeds, or destroyed. The owners who contract scale is small, contract time is short are not decorate to their own greenhouses. Visibly, now needing to focus on improvement of environmental health is not only a tent between public area cleaning weeds, tent area water channel renovation, also including weeds after cleaning, slope after non-woven fabric cover engineering, tent area fences etc.

(3) Insufficient advertising

The traditional concept of Wine is not afraid of deep alley" in the fierce competition in the modern market is no longer applicable, self-packaging, self-marketing is a trend to adapt to the market economic shocks. Being lacking of promoting, base owner should bear the responsibility, 
not just government should bear the main responsibility. At the beginning of the facility agriculture construction, government often coordinate agricultural departments, science and technology departments, banks, owners etc. the interests of all parties, actively pushing forward the construction of the base ideas, finding a way to run projects, raising funds. When the projects completed and the contractions success, the late technical guidance, management services, publicity and promotion are asked less, some small scale, weak and away from roads and towns, enterprises, due to the daily output is too small, it is difficult to attract traders buy products, products in addition to supply the local market, export more difficult. In addition, individual manage door through the media advertising spending big, heavy burden, some enterprises don't even use WeiChat, network and other modern information transmission technology, it is difficult to sell themselves to the consumers, the products produced. Absence of propaganda, traders' buy - purchase - base management difficulties of chain reaction will restrict the further development of the base.

(4) Scattered management right

Management of dispersion is the main reason of the base infrastructure backwardness, the poor public regional health, the less publicity, and the financing difficulties. Currently, the owners of contracting bases greenhouse is amount to one hundred, farmers professional co-operatives, like yongsheng fruit and vegetable seedling cultivation, who contracted 150 greenhouses, but also account for just $1 / 40$ of the 6000 greenhouses, and such a large family is amount to a dozen. Therefore, the overall size of Base is more than $20000 \mathrm{mu}$, is a considerable scale, but management right to the contracted is scattered, is not conducive to carry out unified management, unified planning, unified propaganda, unified maintenance work and so on. Especially when involving the whole interest of the base, such as the base of social construction in public infrastructure, due to the management of scattered into the hands of the people, makes some areas "public products", "non-exclusive benefit" and "noncompetitive consumption" characteristics, each contractor could not pay the price and the "free rider", eventually involves the public interest is difficult to form resultant force do good things.

(5) Backward perception

Perception is the important obstacles of expanding the market influence, enhancing brand image, increasing long-term returns. Mainly including but not limited to the following six aspects. (1) serious Wait-rely-demand thought. In the face of difficulties, the owners didn't actively look for solutions, but more reliance on the government or social organizations, rarely play their own subjective initiative to solve insufficient funds, greenhouses, maintenance, product sales and other issues. (2)the stubborn small peasant consciousness. Greenhouses contractors were mostly peasants, whose cultural level is low, and much emphasis on short-term gains, and ignore the long-term investment, limited horizon production growth, income growth, only calculating the investment amount, whether or not the way, the method adopted by the affect future earnings, the infrastructure, supporting facilities, brand image and sales channel construction investment is few or no, the kind of "the small peasant consciousness" will seriously damage the base for long-term development.(3) the poor disaster prevention awareness. The greenhouses skeleton, films and other auxiliary facilities are obsolete, but some owners will not be maintained for a long time to simply cut cost input, the ability to withstand natural disasters is falling, often cause unnecessary losses. In addition, bases always release the warning information of the insects disasters from time to time, hope the owner take timely measures to defense, spraying pesticide, but also some owners did not cause enough attention. (4) the poor financial risk consciousness. In the face of the financial deficit, the first thought is free of government capital, the second thought is free money of family and friends, rather than the low interest rates funds for supporting agriculture which were from bases, on the one hand reflected the unwilling to bear the financial risk, on the other hand also reflected the low self-confidence to business profitability. (5)blindly believing in "model" in Shandong consciousness strongly. Regardless of the actual local, some owners rely on the paraphrase of the Shandong agricultural facilities construction and development experience, the lack of applicability discrimination, cause some unnecessary loss.6) be lack of market consciousness. Owners planting vegetables and other products more species and amounts depended on the feeling and herd behavior, 
were lack of market understanding, analysis, were easy to cause excess production capacity, product backlog.

(6) Being lack of agricultural science and technology talents, and being backward of scientific research system

Agricultural science and technology talents graduated from department of horticulture college are less than 10\%, professional and technical services and technical personnel in the main production area cannot satisfy the basic needs of agriculture development, villages and towns at the grass-roots level is not related institutions, all these lead to lack of some advanced practical technology popularization, standardized production level is not high, scientific and technological innovation ability is poor. Leading enterprises of vegetables are lack, vegetable industry chain system is incomplete, transportation channel is not smooth in farm easily backlog, vegetables post-processing technology is weak, all these lead to low value-added products, and not conducive to foreign exchange earning and income growth.

\section{Third, Facility Agriculture Development Countermeasures in Longdong •}

(1) Equipment agricultural infrastructure in a timely manner

Facility agriculture can overcome traditional agriculture "weather" passive situation, mainly adopts the advanced modern closed greenhouses, it is extremely difficult to withstand natural disasters if there are not greenhouses main body frame, rolling machine and other infrastructure and related facilities, facility agriculture has lost the existence significance. Based on this research, we found that the planting base of agricultural infrastructure and supporting facilities obsolete, severe destruction of the truth, the relevant departments must regularly check, supervise and urge the owner to maintain greenhouse films, frame, main wall, water-saving irrigation equipment, etc., at the same time with no casual inspection, maintenance, agricultural facilities play an important role to withstand natural risk, market risk, diseases and pests disaster etc.

(2) The appropriate scale operation

With the continuous improvement of people's living standard and vegetables processing varieties increased, agricultural production area still has the very big development space. Depending on enlarging the scale of agricultural production facilities, increasing income is the rational choice of the current adjustment of planting structure, according to the different geographical conditions and characteristics, according to local conditions, the principles of mass production, the comparative advantage obviously, all villages and towns should reasonable arrange and distribute, choose the development potential of leading products, unified planning, continuous construction, scale operation. In xifeng, along the highway, breaking the township village administrative boundaries, concentrated continuous development of new facilities agricultural production base, the implementation of mass production, striving to build an important facilities of agricultural production zone, forming regional advantages and scale advantages, occupying the market by the scale.

(3) Strengthen the government's propaganda promotion

The government should actively take on the role of marketing promote, make full use of television, Internet, radio, newspapers and other media, in the form of popular forms, one thousand ways to expand the social influence, propaganda fruits and vegetables base location, production condition, business operation conditions and infrastructure, building base, brand image, create a good social atmosphere, get the attention and support of the governments at all levels and relevant departments and the social parties.

(4) Cultivate thinking consciousness

Consciousness cultivation includes the market financing, research, innovation, service, brand at least, such as ideological cultivation. The market is the power of developing facilities agriculture, the market makes the vegetable products production, processing, distribution, technical service and so on gradually standardize and industrialize. Therefore, to further improve the facility agriculture economic benefit is to improve the production and marketing service network, and expand sales channels. To vigorously develop the external market is to expand the circulation area, is to organize 
Special Forces to collect, analyze and research the information all the year in the surrounding cities and regions. Build a base for vegetable research and sales window, with the domestic each big vegetable wholesale market information network, maintain rapid reflect the situation of market information. And base on information and market guidance service mechanism of vegetable production. Meet through the organization of supply and demand, product forms, such as the facilities agricultural production base with more vendors to sign the purchase and sale agreement, make the vegetable production is more stability and purpose, to reduce the randomness and blindness. Using vegetable processing technology, development of dehydrated vegetable varieties in the winter and spring were production, strengthen the vegetables listed before the treatment, fresh-keeping and processing and packaging technology popularization and application of extension of pollution-free green vegetable production process, improve the facilities agricultural product added value, and ultimately make agricultural production facilities and sales service series, product industrialization way. On base of brand, urged to form a group of appropriate scale, management norms, stable performance, product quality stable agricultural leading enterprises, build up my confidence in the base of all enterprises, drive the base transformation and upgrading of industrial structure, and realize the economic benefit increased year by year trend. Participate in the base of new research and development, actively seek and scientific research institutions, institutions of higher learning, agriculture leading enterprise technology development and cooperation, promote the transformation of high-tech achievements. Bold innovation marketing mode, highlights the modern consumption concept, development experience leisure agriculture, enhancing the added value of the base product. Reasonable layout, optimize the structure of the existing greenhouse, beautify the environment, improve the quality of construction, reasonable use of resources, improve the utilization of resources, facilities agriculture to reduce agricultural production costs.

\section{References}

[1]Yong-xin Xie, Fang-qin Li, province facility agriculture development present situation, problems and countermeasures research in zhuanglang gansu [J], Chinese gardening abstract, 8, 2012.

[2] xiao-dong guo, study on facilities agriculture development present situation and the problems in zichang county [D], northwest agriculture and forestry university of science and technology graduate thesis, in May 2013.

[3] Jian-ye Shi etc., facility present situation and development countermeasures of agricultural production in half arid areas in central gansu [J]. Modern agricultural science and technology, 2012, 5.

[4] Zheng Zhang, Xue-yu Liu, facility agriculture development present situation and the countermeasures in china[J], agricultural economic problems, 5, 2015. 